\title{
Experimental Study of Power Quality in Wind Farms
}

\author{
F. Oliveira ${ }^{1}$, A. Madureira ${ }^{2}$, M. P. Donsión ${ }^{3}$
}

\author{
${ }^{1}$ E-mail: ftadeu@yahoo.com; ${ }^{2}$ E-mail: andremadureira@yahoo.com; \\ ${ }^{3}$ Department of Electrical Engineering, E.T.S.I.I., University of Vigo \\ Lagoas - Marcosende, 36202 Vigo (Spain) - Phone: +34 986 812685, Fax: +34 986812601 \\ E-mail: donsion@uvigo.es
}

\section{Introduction}

This paper intends to be part of a broader study around the wind energetic exploitation of wind farms. The work behind it had the objective of obtaining experimental data of the working of the wind turbines in the Sotavento Experimental Wind Farm (SEWF) in Galicia, Spain retrieving information about the levels of flicker and harmonics.

Such a new and yet unexplored field of studies as that of the non-conventional energy forms will imply a measurement campaign of wider range than that of the present one, time-wise and spacewise (i. e. longer measurements on a larger number of facilities) due to the randomness associated with the atmospheric phenomena.

From that perspective, factors such as inherent seasonality and correlations between wind regimes and energy production levels cannot be neglected; moreover, given the fairly high level of randomness and some lack of knowledge over the system variables, a larger, statistically more significant amount of data would be required in order to establish any legitimate conclusions.

Based upon a relatively short period of measurement time, this study aims mainly at achieving an adequate data and prior conclusions structuring, possibly providing a reference to future, more thorough studies of wind farms in the region.

The significant lack of data, especially concerning technological details, about the various components of the facility, is largely due to the fact that it is an experimental wind farm, holding various sets of distinct technology wind turbines, and constituted a serious hindrance in the research effort.

Until the present day, many have been the researchers and engineers dedicating time and effort to the Power Quality issue. Indeed, this is presently a central, fast growing concern in this area, in subjects like Power Supply Quality and Voltage Wave Quality, gathering attention from experts worldwide.

This paper will hopefully constitute a useful contribute to the general study of subjects in this area inside the particular case of wind turbines installed in a wind farm.

\section{Field Measurements in the SEWF}

Inaugurated in June 2001, the Sotavento Experimental Wind Farm presents an innovative concept, contemplating two different lines of action: one, technical-commercial and other, educational-formative.

The SEWF is located in Galicia, NW of the Iberian Peninsula, at an altitude of $600 \mathrm{~m}$, in Serra da Loba mountain between the Spanish provinces of La Coruña and Lugo only $10 \mathrm{~km}$ from the famous Pontes de García Rodríguez Coal Power Plant. The average wind speed is 7.5 $\mathrm{m} / \mathrm{s}$, with predominant wind directions $\mathrm{SW}$ and NE.

Its main distinctive feature is a large degree of technological diversity, with five different generation models. It holds a total of 24 wind turbines, three of which are prototypes.

It has a total of $17.56 \mathrm{MW}$ installed capacity, with an annual estimate production of 38500 MW.h. That is the energy equivalent of 68000 oil barrels.

The SEWF is exploited by SOTAVENTO GALICIA, S.A. which is detained in $51 \%$ by public entities (Sodiga Galicia, INEGA and IDAE). The remaining $49 \%$ is detained by the private sector: Unión Fenosa Energías 
Especiales, Endesa Cogenaración y Renovables, Iberdrola Diversificación and Engasa.

The measurement campaign took place over three weeks, at three measuring points, in two different wind turbines and in the wind farm substation. The measuring equipments used were one 'MEMOBOX 300 smart' unit and two 'Unilyzer 812' units.

The 'MEMOBOX 300' and the 'Unilyzer 812' perform power quality measures according to international standards applicable to the system quantities, and analyses results according to European standard EN 50160. Both are capable of gathering and appropriately storing (the Unilyzer 812 requires an external computer unit) voltage harmonics and flicker, among other quantities.

\section{Graphical and Wave Quality Analysis}

\section{Graphical analysis}

A first approach to dealing with a considerable amount of data, concerning different quantities with not very well known relations, should be a graphical analysis. Software tools for drawing time $v s$. level plots are provided with both measurement equipments.

A quick survey of the plots thus obtained suggests some practical conclusions, and may be confirmed as "rules of thumb" to be used when dealing with this set (and possibly other sets) of data:

- three-phase symmetry is quite good (low unbalance), therefore one-phase analysis suffices;

- dominant harmonics remain the same throughout the measurement period, and coincide in both the wind turbines and the substation;

The evolution of several quantities in both the wind turbines assessed and the substation is quite similar, proportionally to nominal voltage. Consequently, a small sample of graphics is included for example purposes only.

The plots in figures 1 to 4 depict the evolution of some of the quantities involved in the study, in both wind turbines, in ten-minute periods over one week.
Visibly, flicker levels are excessively high, while voltage levels are quite stable and unbalance is low. The traditionally most significant harmonics $\left(3^{\text {rd }}, 5^{\text {th }}, 7\right.$ th and $\left.11^{\text {th }}\right)$ are the dominant harmonics, despite their proportionally low values. Considerable levels of harmonics $35^{\text {th }}$ and $37^{\text {th }}$ (and $36^{\text {th }}$, not depicted) in both wind turbines were unexpected, and raise questions on the conversion process. Voltage inter-harmonics measurements in wind turbine 2 provided important values, showing a "bandwidth" phenomenon rather than discrete frequencies resulting from wind energy conversion. Still, data resulting from this study has to be balanced with the experimental vocation of this particular wind farm.

\section{Normative Reference}

Renewable energy production in general, and wind energy in particular, poses a handful of new questions regarding power quality in production. Where correct evaluation of power disturbances is a natural objective in power system knowledge, the study of new sources of such disturbances is vital to maintaining an acceptable level of quality in the networks.

Studies on power quality are quite common in transport and distribution networks, according to procedures defined in the EN 50160 Standard and in the Electromagnetic Compatibility Standard EN 61000 series, but until now are quite rare in production, as the power wave output of conventional power plants is nearly perfectly sinusoidal. Most measurement device manufacturers, including those of the equipments providing data for this paper, also follow such rules and recommendations when designing their apparatuses.

Generally accepted reference values limiting the quantities involved in power quality in production are yet to be adopted, and the usual quality standards have yet to be adapted or reformulated to respond to the power quality disturbances issues in this sub-sector. Reference values can only be found in contractual clauses (defined discretionally and somewhat erratically) between promoters and network operators, or stated by producers' associations in countries where wind energy is more widely spread.

Due to such lack of reference, instead of strictly following the various standards, this analysis will adopt a critical view towards such aspects where 
standards are incompatible with the wind farms case. As an example, the seven-day period usual in electromagnetic compatibility standards is clearly insufficient in systems subject to considerable fluctuations (wind speed, mainly) and seasonal behaviour. Much like the solution adopted by the EN 50160 standard - the values of which refer to "worst-case scenarios", not desirable or adequate values for a power system - the conclusions withdrawn from this sort of study should be interpreted as merely indicative, but never as a declaration of compliance with up to date applicable standards, or otherwise.

\section{Wave Quality}

Where Power Quality is concerned, the analysis of quantities in each wind turbine is somewhat similar to asserting whether it could be adequately connected to the grid, since such an analysis highlights the particular contribution of the turbine operation to the overall disturbance introduced by the wind farm.

Where used wisely, it can provide a basis for technological comparison between different makes/models of wind turbines.

Wind Turbine 1 - Analysis according to EN $\underline{50160}$

Basic statistics on the data, by comparison to the European Standard EN 50160, highlighted the following: (Figure 5)

- voltage exceeds $+/-10 \%$ only in 6 of the 2999 measurement intervals considered (by far less than the $5 \%$ allowed by the standard);

- the values for harmonic components (voltage harmonics) are relatively low, even for the usually more significant harmonics - never surpassing $1.22 \%$ in $95 \%$ of measurement intervals;

- long-term flicker, Plt, has a maximum value $(95 \%)$ of 2.52 , which largely exceeds normative recommendation $(\mathrm{Plt}=1)$. This denounces high values of short-term flicker for long periods of time;

- unbalance and total harmonic distortion values are comparatively low, respectively $0.15 \%$ (maximum of 2) and $1.55 \%(8 \%)$.

Wind Turbine 2 - Analysis according to EN $\underline{50160}$
In spite of substancial constructive differences between the wind turbines studied, the analysis results are very similar: (Figure 6)

- measured voltages are always within the $+/-10 \%$ limit;

- voltage harmonics are lower, comparetively to WT1 (possibly due to a higher nominal voltage $)-$ not surpassing $0,85 \%\left(7^{\text {th }}\right.$ harmonic)

\section{Conclusions and Outlook}

The experimental data suggests flicker as the most severe problem affecting power quality in this wind farm, as it surpasses the limit-values set by the EN 50160 standard.

The phenomena and characteristics observed in the measured quantities provide some clues to further exploring of the present data, namely using statistical tools.

\section{Acknowledgement}

The financial support from the "Ministerio de Ciencia y Tecnología", DPI2002-04416-C04-02 Project, and from "Xunta de Galicia", PGIDIT03PXIC30308PN project, is gratefully acknowledged.

\section{References}

[1] A. Madureira; F. Oliveira. Qualidade da onda de tensão em parques eólicos - harmónicos e flicker. Graduation Project, 2003.

[2] M. P. Donsión. Calidad de Potencia en los sistemas de energía eléctrica: perspectivas futuras. Depto. de Ingeniería Eléctrica de la Universidad de Vigo, 2002.

[3] M. Bollen. Understanding Power Quality Problems: Voltage Sags and Interruptions. IEEE. New Jersey : John Wiley \& Sons, Inc., 2000. ISBN 0-7803-4713-7. 


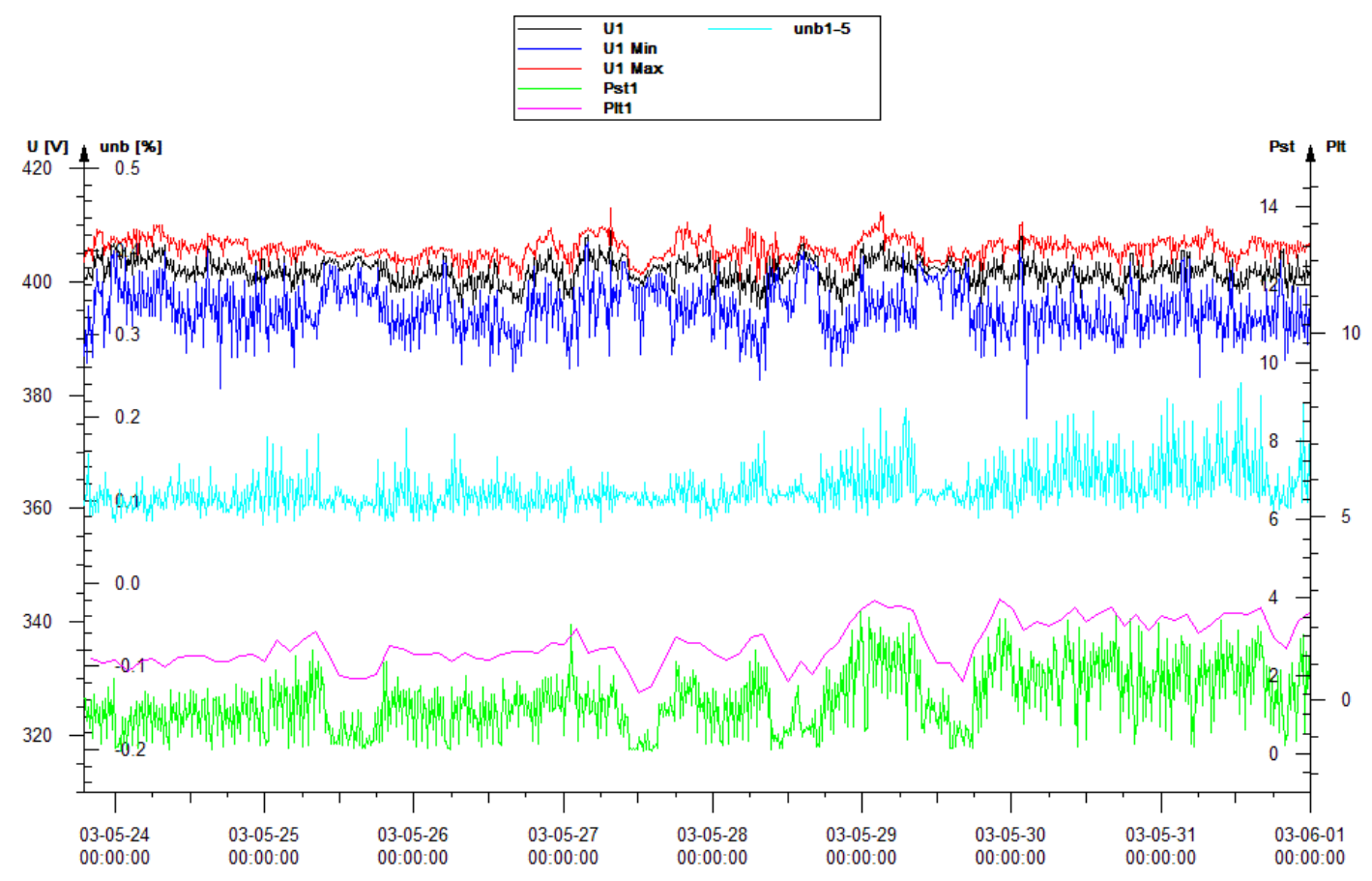

Figure 1 - Maximum, minimum and average voltage output, short-term and long

term flicker, and unbalance measured in the output of Wind Turbine 1.
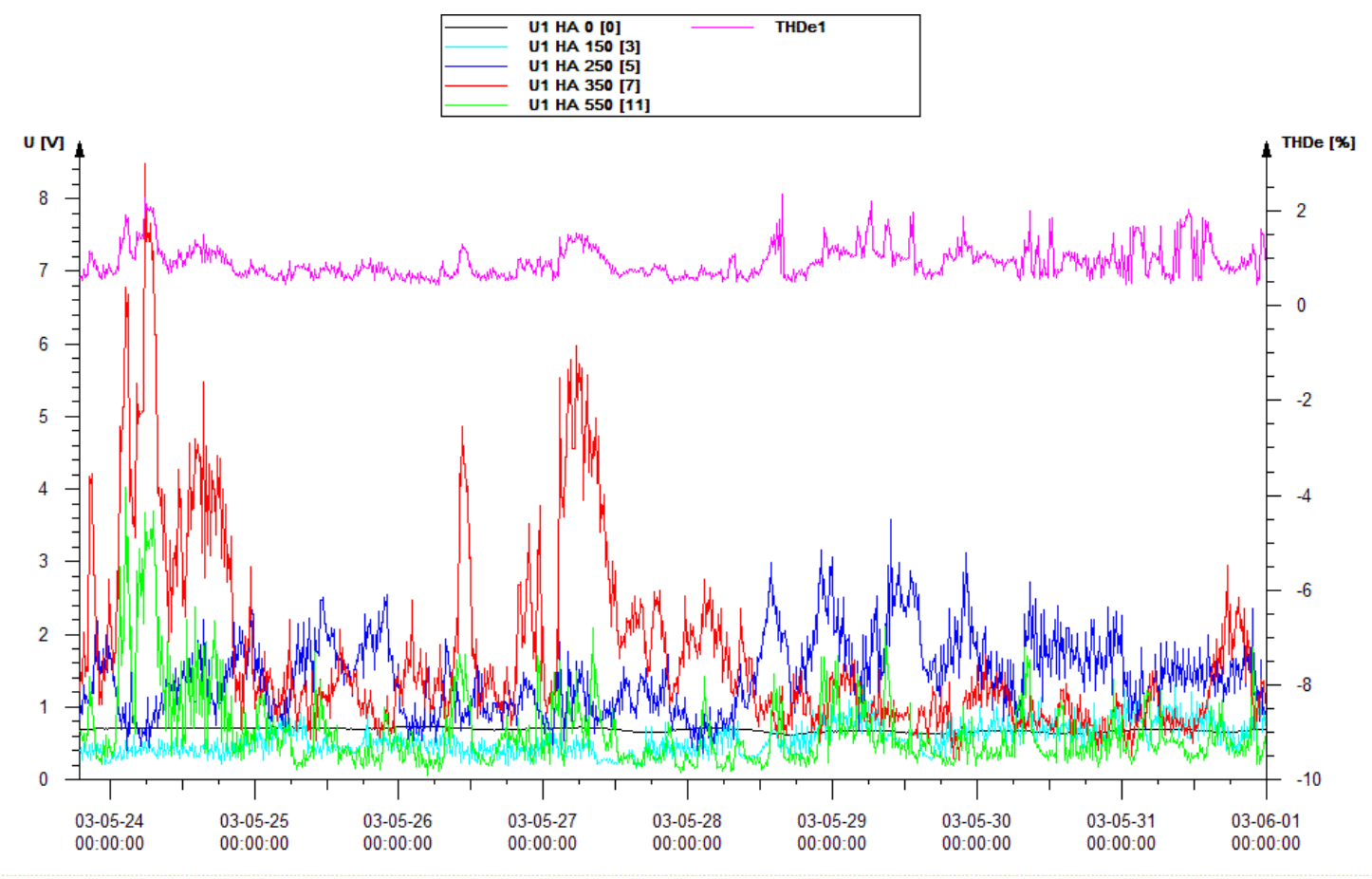

Figure 2 - European THD, $3^{\text {rd }}, 5^{\text {th }}, 7^{\text {th }}$ and $11^{\text {th }}$ voltage harmonics, and DC component measured in the output of Wind Turbine 1. 


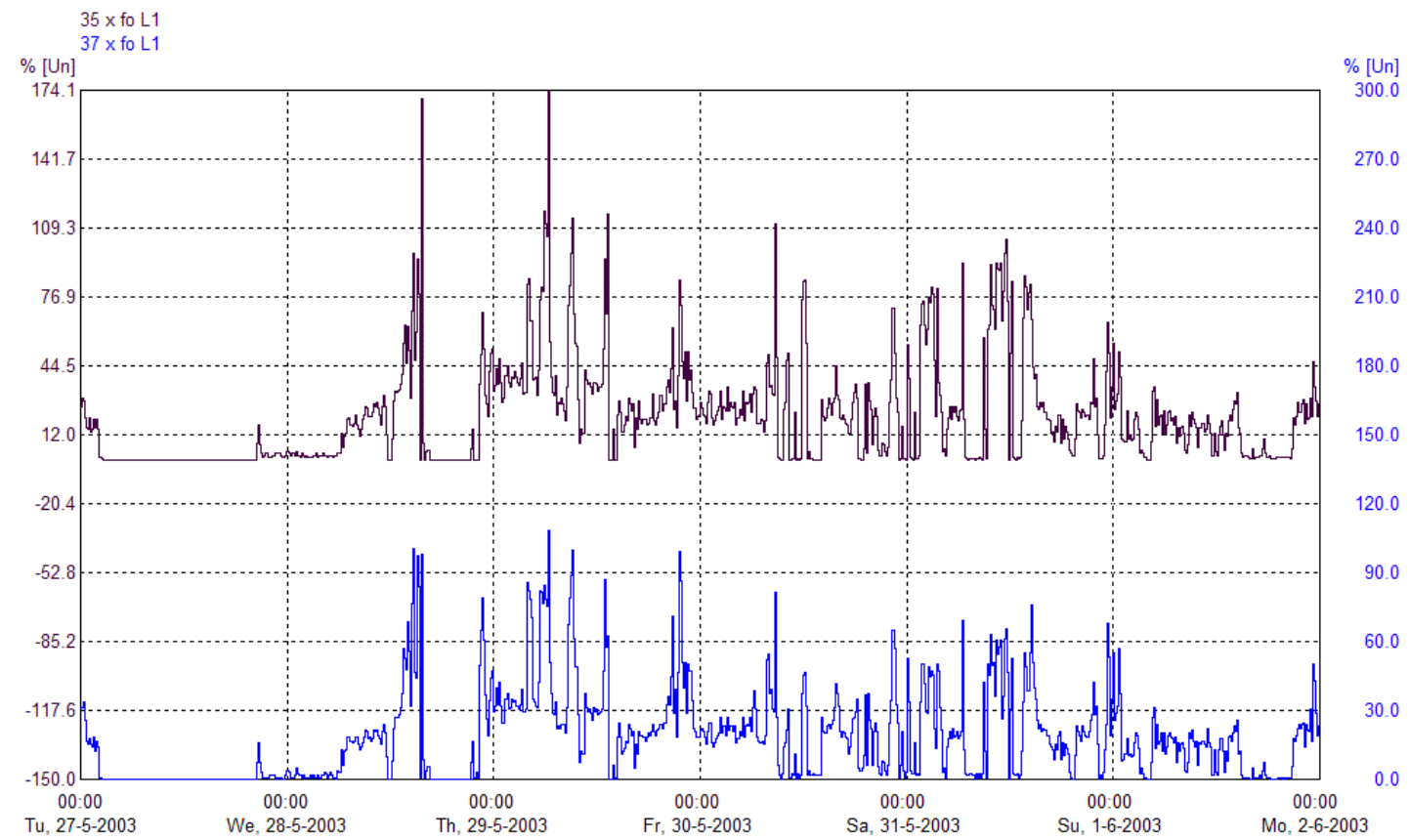

Figure $3-35^{\text {th }}$ and $37^{\text {th }}$ voltage harmonics measured in Wind Turbine 2

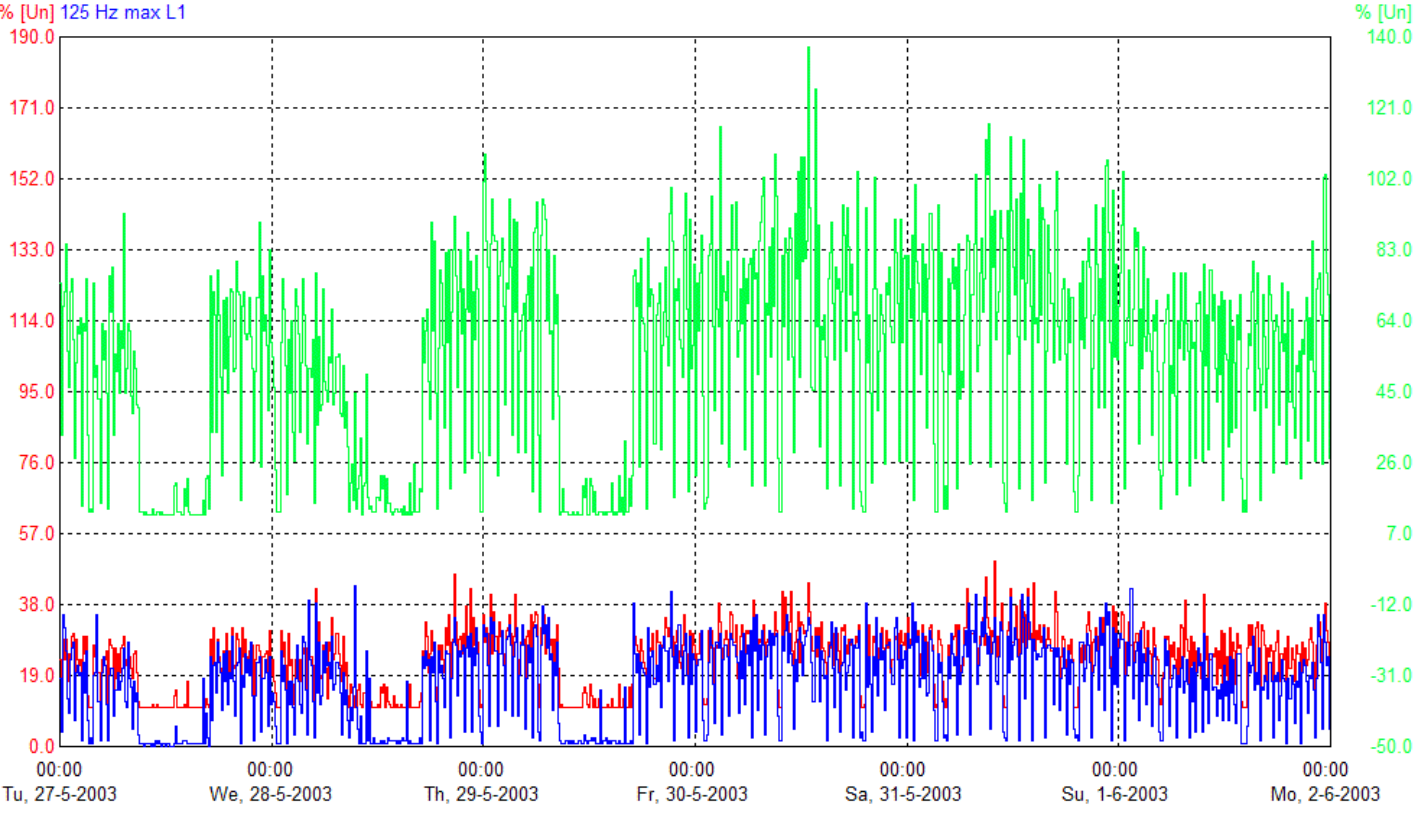

Figure 4 - $25 \mathrm{~Hz}, 75 \mathrm{~Hz}$ and $125 \mathrm{~Hz}$ voltage inter-harmonics measured in Wind Turbine 2 


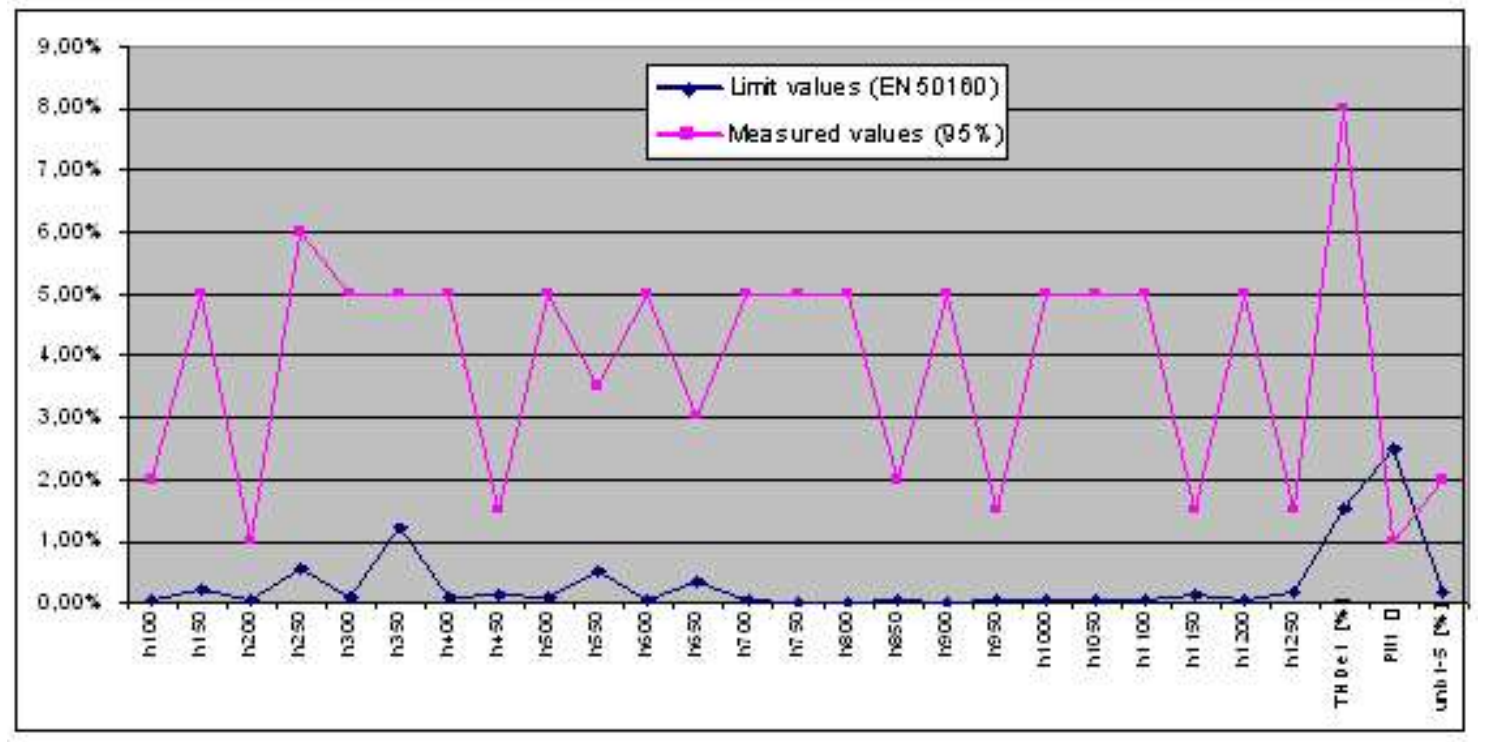

Figure 5 - Measured values $(95 \%)$ vs EN 50160 reference values in Wind Turbine 1

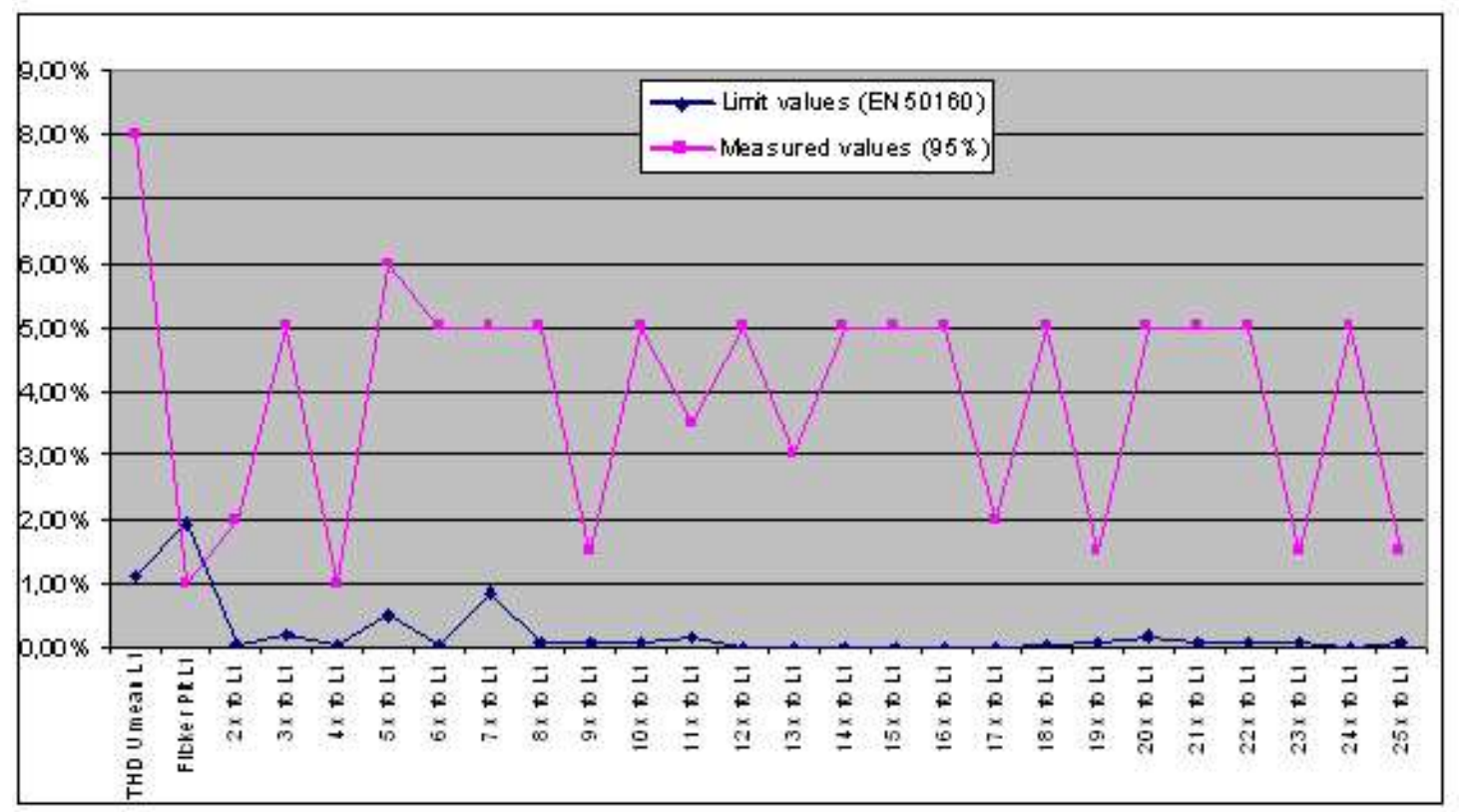

Figure 6 - Measured values (95\%) vs EN 50160 reference values in Wind Turbine 2 